Revista Kinesis, Santa Maria v.36, n.3, p. 91-101, set-dez. 2018

Centro de Educação Física e Desportos - UFSM

DOI: $105902 / 2316546431177$

Data de submissão: 16-02-2018

Data de Aceite: 21-11-2018

\title{
O ENSINO DO ESPORTE SEGUINDO UMA ABORDAGEM CRÍTICO-EMANCIPATÓRIA: APROXIMAÇÕES COM O MODELO SPORT EDUCATION
}

\author{
SPORTS EDUCATION FOLLOWING A CRITICAL-EMANCIPATORY APPROACH: APPROXIMATIONS WITH THE \\ SPORT EDUCATION MODEL
}

\section{LA ENSEÑANZA DEL DEPORTE SIGUIENDO UN ENFOQUE CRÍTICO-EMANCIPATORIO: APROXIMACIONES CON EL MODELO SPORT EDUCATION}

Tairone Girardon de Vargas

tairone_vargas@hotmail.com

Universidade Federal de Santa Maria - UFSM

Maríndia Mattos Morisso

marindiamorisso@gmail.com

Universidade Federal de Santa Maria - UFSM

\author{
Rosalvo Luis Sawitzki \\ rosalvols@hotmail.com \\ Universidade Federal de Santa Maria - UFSM
}

\section{RESUMO}

Este artigo tem como objetivo analisar possíveis aproximações entre a abordagem critico-emancipatória e o modelo de ensino Sport Education nas aulas de Educação Física que tematizam o esporte. Para isso, apresentamos uma revisão bibliográfica utilizando dos principais autores que tratam dos assuntos (KUNZ, 2010; SIEDENTOP, 1994). A partir do levantamento das características da abordagem e do modelo de ensino realizamos uma aproximação entre eles. Interpretamos que ambos apresentam características potenciais que podem auxiliar na prática pedagógica, pois enfatizam a aprendizagem do aluno e também contribuem para o processo de inovação por parte do professor.

Palavras-Chave: Educação Física; Esporte; Ensino

\section{ABSTRACT}

This article aims to analyze possible approximations between the critical-emancipatory approach and the Sport Education teaching model in the Physical Education classes that theme the sport. For this, we present a bibliographical review using the main authors that deal with the subjects (KUNZ, 2010; SIEDENTOP, 1994). From the survey of the characteristics of the approach and the teaching model, we make an approximation between them. We interpret that both have potential characteristics that can aid in pedagogical practice, since they emphasize student learning and also contribute to the teacher's innovation process.

Keywords: Physical education; Sport; Teaching

\section{RESUMEN}

Este artículo tiene como objetivo analizar posibles acercamientos entre el enfoque crítico-emancipatorio y el modelo de enseñanza Sport Education en las clases de Educación Física que tematizan el deporte. Para ello, presentamos una revisión bibliográfica utilizando de los principales autores que tratan de los asuntos (KUNZ, 2010, SIEDENTOP, 1994). A partir del levantamiento de las características del enfoque y del modelo de enseñanza realizamos una aproximación entre ellos. Interpretamos que ambos presentan características potenciales que pueden auxiliar en la práctica pedagógica, pues enfatizan el aprendizaje del alumno y también contribuyen al proceso de innovación por parte del profesor. 


\section{Introdução}

A Educação Física passou ao longo dos anos por diferentes movimentos que a influenciaram. A saúde, o esporte e a instituição militar fizeram parte dessa história de transformações, pois, para que a Educação Física pudesse se constituir como importante precisava desenvolver as necessidades da sociedade de acordo com a evolução cultural da nação (BRACHT; GONZÁLEZ, 2005). Segundo Bracht (1997, p. 17) nesse período "[...] a Educação Física, no Brasil, [desenvolveu] sua identidade seus códigos, a partir da relação que estabeleceu/estabelece com um meio ambiente que compreende, fundamentalmente, a instituição escola, a instituição militar e a instituição esporte". Diante disso, a principal finalidade da Educação Física era o "exercitar-se para", ou seja, "exercitar para melhorar a saúde, exercitar para formar o caráter, exercitar para o desenvolvimento do homem integral" (GONZÁLEZ; FENSTERSEIFER, 2009, p. 12).

O esporte (influência que daremos destaque neste trabalho) teve um grande impacto, particularmente, entre os anos 1965 e 1985. Segundo González e Fensterseifer (2009, p.10), nesse período, "a EF estabeleceu uma relação simbiôntica com o esporte, por meio da qual esse fenômeno, em sua forma institucionalizada, acabou sendo praticamente hegemônico nas aulas de EF". O Esporte entrou na Escola tornando as aulas de Educação Física uma "prática desportiva [...], 'massificada', para daí brotar os expoentes capazes de brindar o país com medalhas olímpicas" (GHIRALDELLI JR.,1988, p. 20).

De acordo com Oliveira (1983, p. 77) a "colocação da Educação Física como sinônimo de esporte induz a concebê-la, essencialmente como competição, e cria o recorde como o seu objetivo fundamental". Segundo Bracht (1997, p. 22) a Educação Física neste período baseou-se no "princípio do rendimento atlético-desportivo, competição, comparação de rendimentos e recordes, regulamentação rígida, sucesso esportivo é sinônimo de vitória, racionalização de meios e técnicas". Portanto, nesse período a Educação Física Escolar assumiu “códigos de uma outra instituição, e, de tal forma, que temos então não o esporte da Escola, e sim o esporte na Escola" (BRACHT, 1997, p. 22).

A partir dos anos 80 ocorreu o movimento renovador da Educação Física no Brasil. Esse movimento incentivou significativas mudanças na área, pois teve como objetivo "[...] demostrar e afirmar que [a Educação Física] possui, assim como os outros componentes curriculares, um conhecimento, um saber (inclusive conceitual) necessário à formação plena do cidadão" (BRACHT; GONZÁLEZ, 2005, p. 153) que vai além de reproduzir propostas de instituições, como o esporte. No entanto, apesar do avanço acadêmico que o movimento provocou, sabe-se que o ambiente escolar e as atuações dos docentes, dificultam o reconhecimento da Educação Física como uma disciplina de conhecimento e não mais como simples atividade (BRACHT; GONZÁLEZ, 2005).

Diante disso, González e Fensterseifer (2009) comentam que para a Educação Física se legitimar enquanto componente curricular a partir dos objetivos pensados no 
movimento renovador, é necessário que se construam "novas" práticas pedagógicas criadas pelos docentes que se encontram no ambiente escolar. Porém, isso ainda é difícil, pois atualmente a Educação Física “se encontra 'entre o não mais e o ainda não', ou seja, entre uma prática docente na qual não se acredita mais, e outra que ainda se tem dificuldades de pensar e desenvolver" (GONZÁLEZ; FENSTERSEIFER, 2009, p. 12).

Nesse sentido, Darido (2012) destaca que diferentes abordagens foram discutidas ao longo dos anos na tentativa de desconstruir a imagem de que se trata de um componente curricular mecanicista, esportivista e tradicional. Segundo a autora essas abordagens são: Humanista; Fenomenológica; Psicomotricidade, baseada nos Jogos Cooperativos; Cultural; Desenvolvimentista; Interacionista-Construtivista; Crítico-Superadora; Sistêmica; CríticoEmancipatória e Saúde Renovada. Entretanto, as abordagens que na maioria das vezes predominam são as esportivistas e de forma superficial, ou seja, "apenas na ótica do saber fazer, o que acaba limitando a perspectiva do que se ensina/aprende, do conhecimento produzido pela humanidade sobre a cultura corporal” (DARIDO, 2012, p. 46).

Segundo Carlan, Kunz e Fensterseifer (2012, p. 57) "o esporte se constitui na prática corporal mais citada e valorizada pelos alunos, apesar de, num modo geral, estar atrelada a um modelo tradicional/paradigma da racionalidade instrumental”. Na maioria das vezes, esse modelo exclui alguns alunos da aula de Educação Física por não proporcionar condições de aprendizagem a todos os níveis de desempenho. Além disso, destaca-se que "ensinar esporte" não é somente praticar, já se discute sobre a "necessidade de que a teoria/prática esportiva, enquanto parte do conteúdo a ser ensinado na escola, deve ser mediada por uma teoria pedagógica crítica, reconhecendo o esporte como um fenômeno socialmente produzido". (CARLAN; KUNZ; FENSTERSEIFER, 2012, p. 57).

A partir destas observações, é importante discutir que "a realidade escolar tem mostrado que os professores de Educação Física encontram dificuldades em modificar suas práticas pedagógicas no ensino do conteúdo Esportes, na perspectiva de superar o paradigma da racionalidade instrumental" (CARLAN; KUNZ; FENSTERSEIFER, 2012, p. 58). Portanto, com a intenção de dialogar sobre os saberes que oportunizam indicações iniciais de um processo de ensino-aprendizagem que supere as atividades exclusivamente tecnicistas no ensino do esporte nas aulas de Educação Física, propomos neste trabalho analisar possíveis aproximações entre a abordagem critico-emancipatória (KUNZ, 2010) e o modelo de ensino Sport Education (SIEDENTOP, 1994).

De maneira mais específica, apresentamos neste artigo a descrição do ensino da temática esporte nas aulas de Educação Física a partir da abordagem crítico-emancipatória. Na sequência buscamos explicar os objetivos do modelo de ensino do Sport Education na perspectiva de não negar o ensino do esporte, mas sim vislumbrar de um planejamento que supere a crítica e proporcione autoria aos agentes envolvidos, ou seja, que os alunos não apenas reproduzam, mas sejam atores desse processo. 


\section{Procedimentos Metodológicos}

Os procedimentos metodológicos deste artigo basearam-se em uma revisão bibliográfica. Segundo Gil (2002) esse tipo de pesquisa desenvolve-se a partir da leitura de trabalhos já produzidos sobre o assunto. De acordo com o autor, a revisão bibliográfica permite ao "investigador a cobertura de uma gama de fenômenos muito mais ampla do que aquela que poderia pesquisar diretamente" (GIL, 2002, p. 45).

Para este artigo em específico desenvolvemos a revisão a partir de dois assuntos: a abordagem crítico-emancipatória e o modelo de ensino Sport Education. Para tratar da abordagem utilizamos de seu principal autor Kunz (2010), já para discutir o modelo de ensino nos baseamos na referência de Siedentop (1994) e outros autores que utilizaram do Sport Education em diferentes lugares do mundo: Graça e Mesquita (2007); Calderón, Hastie e Pérez (2011); Ginciene e Matthiesen (2017).

A partir da leitura e levantamento das principais características da abordagem crítico-emancipatória e do modelo de ensino Sport Education realizamos uma aproximação dos dois assuntos para discutir as aulas de Educação Física que tematizam o esporte. Diante disso, buscamos avaliar em que medidas a abordagem e o modelo, juntos, podem colaborar para a superação do ensino tradicional das diferentes modalidades.

\section{Resultados e Discussões}

\subsection{A abordagem Crítico-Emancipatória}

As discussões que apresentamos na introdução apontam que após o movimento renovador, o ensino dos esportes nas aulas de Educação Física foi alvo de diferentes interpretações por parte dos professores. Alguns docentes tiveram dificuldades para repensar as aulas. Em geral, essa influência esportiva, e as demais demandas da sociedade interferiram na prática pedagógica.

Nesse sentido, podemos observar o trabalho de Machado e Bracht (2016), que investigou o impacto na identidade docente dos professores que passaram pela ressignificação da Educação Física no movimento renovador. Diante da investigação feita pelos autores, identificamos que as dificuldades das práticas pedagógicas não estavam diretamente relacionadas ao docente, mas também as alienações da Educação Física. Assim, Machado e Bracht (2016 p. 859), descrevem o movimento renovador

[...] não somente como resultado de uma "experiência cognitiva mal sucedida" - como se a "culpa" fosse dos professores que não compreenderam bem o que estava sendo proposto, e daí o não sucesso da empreitada - mas, também, como consequência da contraposição (ou do impacto!) de expectativas normativas alimentadas para a $\mathrm{EF}$, tendo sido fator determinante a relação afetiva dos docentes com o esporte. 
A partir desse contexto, Kunz (2010) destaca que diante da necessidade de mudança se passou a questionar e criticar toda a prática pedagógica da Educação Física, não dando a ela, em específico ao professor, suportes para as novas perspectivas. Por outro lado, se teve preocupações "com a apresentação de um modelo alternativo sem questionamentos profundos, especialmente sobre a relevância sociopolítica e educacional dessa alternativa" (KUNZ, 2010, p.17). Trata-se da necessidade de superar a crítica já feita à área, auxiliando a pensar e emancipar uma prática pedagógica para dar conta das manifestações da cultura corporal de movimento.

Segundo Kunz (2010) a abordagem crítico-emancipatória pode ser considerada uma possibilidade para pensar a prática pedagógica superando a perspectiva tradicional. De acordo com o autor, a abordagem apresenta potenciais para o ensino dos esportes, pois se preocupa com o "desenvolvimento do aluno em relação a determinadas competências imprescindíveis na formação de sujeitos livres e emancipados" (2010, p.29). Nesse contexto, emancipar significa oferecer ao aluno o desenvolvimento de saberes que deem conta do saber praticar de forma autônoma, promovendo assim a possibilidade de reconhecer diferentes manifestações da cultura corporal de movimento na sociedade.

Sobre esse saber praticar apontamos a definição trazida por González e Fraga (2009). Para os autores o ato de praticar deve proporcionar autonomia e significância ao educando, portanto, as aulas não servem como um meio de reprodução dos espaços institucionalizados na Educação Física, mas sim como uma oportunidade de ressignificação do mesmo para um contributo a aprendizagem dos alunos. De forma específica, segundo González e Fraga (2009, p. 120) os objetivos do saber praticar são "desenvolver durante as aulas um tipo de saber prático que leve à apropriação dos elementos necessários para participar, de forma proficiente e autônoma, de práticas corporais recreativas".

Por outro lado, segundo Kunz (2010), a representação do esporte nas aulas de Educação Física pode ser discutida através de dois conceitos. O primeiro, o autor denomina como restrito, ou seja, uma prática relacionada diretamente ao tema esporte e seu conteúdo: "o treino, a competição, o atleta e o rendimento esportivo" (2010, p. 63). Entretanto, o segundo, segue uma abordagem crítico-emancipatória, pois o ensino do esporte nas aulas de Educação Física vincula-se a um sentido amplo, que de acordo com o autor pode ser apresentado como "mundo vivido".

Esse mundo vivido trazido em questão oportuniza fazer uma relação com as finalidades pedagógicas da Educação Física dentro das suas instituições escolares. Isso porque, são nessas condições que a abordagem crítico-emancipatória nos apresenta seis encenações que possibilitam proporcionar um ensino que de condições aos alunos superarem a visão reducionista do ato de praticar o esporte: 
interpretações de diferentes papéis; Entender o papel do espectador; Conhecer o mundo dos esportesqueéencenadoparaatenderaoscritérioseaosinteressesdomercado(KUNZ,2010,p.69).

Nesse contexto, entendemos que a aula de Educação Física que tem como objetivo o ensino do esporte, deve estar articulada a todas as ações desse espaço. Portanto, interpretamos que o esporte quando trabalhado deve "propiciar a compreensão crítica das diferentes formas da encenação esportiva, os seusinteresseseosseus problemas vinculados ao contexto sociopolítico" (KUNZ, 2010, p. 73). Pontualmente, se faz necessário que o componentecurricularpermeieporconhecimentosqueproporcionemrelaçõesdoconteúdo da aula, com o contexto social no qual os alunos e as instituições escolares estão envolvidos.

Desse modo, sobre a perspectiva de encenação do esporte nas aulas de Educação Física, Kunz (2010) destaca que é importante pensar que essas ações sejam pedagogicamente relevantes. Portanto, interpretamos que uma alternativa para o desenvolvimento das perspectivas pensadas na abordagem crítico-emancipatória no ensino do esporte pode ser a utilização do modelo Sport Education. Desse modo apresentamos no próximo tópico os objetivos e as características do referido modelo, apontando possiblidades para sua integração nas aulas de Educação Física.

\subsection{As características do modelo de ensino Sport Education}

O modelo de ensino Sport Education tem como objetivo reestruturar o esporte nas aulas de Educação Física, proporcionando aos alunos elementos como a "[...] competência desportiva, o da literacia desportiva e o do entusiasmo pelo desporto, sendo o seu propósito formar a pessoa desportivamente competente, desportivamente culta e desportivamente entusiasta" (GRAÇA; MESQUITA, 2007, p. 410). De modo geral, o Sport Education busca desenvolver uma vivência corporal autêntica do esporte, refletida de conhecimento para além da reprodução formal. Portanto, com esse modelo de ensino o aluno tem a possibilidade de se apropriar do esporte como uma forma de representatividade da cultura corporal de movimento.

Para que se ocorra essa vivência autêntica da prática esportiva, o Sport Education utiliza de seis características do esporte institucionalizado: a época esportiva, a filiação, a competição formal, o registo estatístico, a festividade e o evento culminante (SIEDENTOP, 1994). Essas características possibilitam ao aluno fazer parte de um ambiente de aprendizagem, que contempla conhecimentos para além da reprodução exclusivamente prática do esporte nas aulas de Educação Física.

A primeira característica é a época esportiva, conhecida como a unidade didática desenvolvida pelo professor. Na utilização desse modelo a unidade deve atender a alguns requisitos, como um período prolongado de aulas, por exemplo. Essa condição proporciona aos alunos desenvolverem um conjunto de saberes corporais e conceituais sobre os conteúdos trabalhados. O número de aulas deve ser considerado 
a partir dos objetivos da temática estudada, de maneira pontual, a quantidade de encontros deve proporcionar um conhecimento profícuo, ou seja, que a partir dessa intervenção os discentes possam se apropriar da prática fora do ambiente escolar. Além do mais, este planejamento deve oportunizar a realização de uma sistematização corporal dos conhecimentos trabalhados no decorrer da época esportiva.

A segunda característica do Sport Education é a filiação que consiste em oportunizar aos alunos participantes do processo um reconhecimento de sua importância na realização das aulas. Assim, todos de uma maneira ou de outra contribuem no desenvolvimento dos saberes da disciplina. Em palavras mais pontuais, essa característica se refere à organização de equipes, que potencializam funções especificadas para cada membro e trabalham de maneira colaborativa no decorrer da época esportiva. Nesse espaço, cada qual com o seu acervo de experiências auxilia no compartilhamento de saberes em prol do melhor desenvolvimento de seu grupo.

Diante da filiação e estruturação de equipes o modelo de educação esportiva sugere o desenvolvimento de uma terceira característica, definida como competição formal, ou seja, a realização de uma prática autêntica para os discentes participantes do processo. No entanto, esta organização deve superaralguns elementos do mundo institucionalizadoeser conduzida pelo docente a partir de um planejamento que oportunize situações equânimes de disputa e aprendizagem a todos os alunos. Cabe ressaltar que essa competição formal deveser desenvolvidajuntoao cronograma dosconteúdos trabalhados na unidadedidática.

O desenvolvimento da competição interna na turma proporciona o aparecimento da quarta característica, que é o registro estatístico. Esse movimento consiste no levantamento de informações sobre a competição e na divulgação das mesmas. Através disso é possível pontuar os avanços obtidos pela turma, bem como ponderar o alcance das equipes, e as singularidades de cada aluno. O meio de divulgação dessas informações pode ocorrer junto aos murais comuns da escola, redes sociais e também em meios de comunicação próximos utilizados pelos discentes, como a rádio da escola, por exemplo.

A quinta característica, é a festividade, ou seja, um movimento de confraternização que deve ser estabelecido durante toda a unidade didática. Essa característica está presente em todasas outras, pois estabelece umambienteagradável no desenvolvimento das tarefas demandadas pelo Sport Education. O clima festivo estimula o envolvimento dos alunos, fazendo com que se sintam parte do processo. Por fim, a sexta e última característica é o evento culminante. Pontualmente trata-se do fechamento da época esportiva (unidade didática), ou seja, a sistematização. No ensino dos esportes esse encerramento pode ser desenvolvido através de um evento que oportunize uma competição entre as várias equipes das diferentes turmas da escola. O fator determinante consiste em oportunizar aos alunos um protagonismo de seu trabalho e compartilhamento de seus conhecimentos.

A partir dessas características analisamos que a organização e desenvolvimento do Sport Education pode ser uma estratégia metodológica condizente para 
enfrentar as dificuldades de se trabalhar o tema esporte. Esse modelo de ensino ainda pouco explorado proporciona aos alunos uma vivência autêntica da prática esportiva, harmonizando saberes que superam a prática formal.

De acordo com Calderón, Hastie e Perez (2011, p. 75, tradução nossa) esse modelo de ensino proporciona aos professores "um sentimento de renovação 'um sopro de ar fresco', que Ihes impulsiona a melhorar sua formação e certos aspectos de sua intervenção docente". Em relação a esse fato, entendemos que embora seja difícil planejar esse modelo de ensino, o mesmo pode contribuir significativamente para superar a visão exclusivamente prática dos professores de Educação Física proporcionando a eles um ambiente de renovação de suas aulas.

Sobre à relação dos alunos com o Sport Education, os trabalhos apontam sobre duas perspectivas, a aprendizagem e o envolvimento entusiástico dos educandos. Fazendo referência a aprendizagem do alunado Graça e Mesquita (2007, p.412) citam, que o referido modelo “(a) fornece ao aluno tempo para jogar; (b) ensina habilidades com transferibilidade para ojogo;(c)fornece tempo para desenvolverjogadores competentes". Diante do aporte feito, interpreta-se que esse modelo de ensino se difere da reprodução de atividades técnicas descontextualizadas e isoladas, constituindo-se de uma oportunidade dos alunos utilizarem dessas aprendizagens dentro das aulas e também fora delas.

Dessa forma, entendemos que esse modelo de ensino supera as tradicionais práticas esportivas desenvolvidas nas aulas de Educação Física, proporcionando aos educandos possibilidades equânimes de aprendizagem, ou seja, todos têm suas condições de aprendizagens respeitas. Nessa perspectiva, Graça e Mesquita (2007, p. 411) descrevem que "os alunos menos dotados [...], habitualmente marginalizados nos programas tradicionais, sentem que, com os programas de educação desportiva, trabalham mais e dão um contributo importante para a equipe".

Os estudos também mostram que além do Sport Education contribuir para a aprendizagem dos alunos, o modelo oferece um ambiente prazeroso e entusiástico. Segundo o trabalho de Calderón, Hastie e Perez (2011, p.72) "O comentário geral dos alunos depois de experimentar o modelo faz referência à sua percepção da realização de um trabalho mais aplicado, sério e motivador do que nas aulas de educação física que não usam o modelo". Além do entusiasmo e envolvimento dos educandos no referido modelo de ensino, os alunos com menor habilidade desempenham funções tão importantes que os demais na construção e desenvolvimento da sua equipe (CALDERÓN; HASTIE; PEREZ, 2011).

Nessa perspectiva de mudança Mesquita e Graça (2007, p.410) relatam que o Sport Education proposto originalmente por Siedentop no ano 1994 “[...] constitui um modelo curricular que oferece um plano compreensivo e coerente para a renovação do ensino dos jogos na escola, preservando e reavivando o seu potencial educativo". Dessa forma, interpretamos, que essa metodologia de ensino tem potenciais aproximações à abordagem crítico-emancipatória, pois possibilita uma pratica de ensino articulada com os objetivos 
da Educação Física enquanto componente curricular obrigatório da educação básica. No tópico seguinte analisamos uma aproximação entre a abordagem e o modelo de ensino.

\section{3 Aproximações da abordagem Crítico-Emancipatória com o modelo de ensino Sport Education}

As descrições apresentadas ao longo do texto, sobre o ensino do esporte no atual contexto da Educação Física escolar mostram que a prática carece de metodologias inovadoras. Nesse sentido, observando a abordagem crítico-emancipatória e o modelo Sport Education, interpretamos que suas características apresentam potenciais que podem auxiliar em uma prática pedagógica que articule as manifestações da cultura corporal de movimento nas instituições escolares. Essa relação pode ser percebida através da organização e planejamento, tanto da abordagem quanto do modelo, afinal, ambos enfatizam o processo de aprendizagem do aluno e também potencializam o reconhecimento da prática inovadora por parte do professor.

Fazendo referência ao aluno e seu envolvimento no processo de aprendizagem, identificamos que tanto a abordagem quanto o modelo de ensino focam no seu desenvolvimento. Ou seja, seguindo ambas as situações, percebemos que o ato de vivenciar e praticar do discente provoca sentido. Conforme é destacado na abordagem, os conteúdos trabalhados nas aulas fazem parte do mundo vivido. A partir desse espaço o modelo possibilita uma organização para o aluno desenvolver todas as tarefas necessárias para que edifique a aprendizagem.

Para o professor essa articulação também apresenta um potencial, pois possibilita desenvolver um planejamento inovador de acordo com as condições laborais encontradas no seu espaço de trabalho. Isso, por sua vez proporciona ao docente a oportunidade de superar as visões reducionistas do seu trabalho, que acaba sendo desarticulada das condições locais e dos interesses escolares. No entanto, interpretamos que para o desenvolvimento de uma boaprática de ensino, demanda do educador empenho, bemcomo tempo de planejamento para assim suprir os objetivos da abordagem utilizando do modelo.

Contudo, é interessante entendermos que essas articulações iniciais necessitam de um maior aprofundamento, tanto da abordagem quando do modelo. Mas, de maneira geral é possível visualizar uma aproximação entre ambos, pois as objetividades da perspectiva critico-emancipatória oportunizam um sentido a prática pedagógica da Educação Física e o modelo Sport Education pode auxiliar na organização do ensino do esporte, aproximando o mundo vívido do aluno com os conteúdos da disciplina.

\section{Considerações Finais}

A aproximação entre a abordagem crítico-emancipatória e o modelo Sport 
Education é possível, pois, embora apresentadas ao meio acadêmico em períodos diferentes priorizam um ensino centrado no aluno. Nesse caso, a articulação e o estudo dos dois temas proporciona a todos os agentes envolvidos no interior da escola uma ressignificação, em especial do ensino do esporte. Fato esse que pode ser visualizado na pretensão de oportunizar a Educação Física uma superação de prática esportiva desarticulada de um objetivo condizente com as necessidades da sociedade atual.

O diálogo entre o trabalho de Kunz (2010), e o Sport Education, mostra singularidades específicas para superar um ensino reducionista do esporte nas aulas de Educação Física. Isso porque, o foco não são apenas os conteúdos específicos do esporte, como a competição e o desempenho, mas sim, o mundo vivido dos alunos, ou seja, trata-se de desenvolver o esporte a partir das condições laborais e sociais de todos os agentes envolvidos, dando a oportunidade de protagonismo, não somente aos mais habilidosos. Portanto, entendemos que a aproximação da abordagem com o modelo de ensino pode proporcionar aos alunos um processo de ensino-aprendizagem que pontue sobre os objetivos de Educação Física potencializando as diferentes manifestações da cultura corporal de movimento.

Desse modo, compreendemos que a abordagem crítico-emancipatória e o modelo de ensino Sport Education podem ser importantes aliados para superar a reprodução formal e possibilitar ao aluno o interesse pela Educação Física enquanto componente curricular que busca oferecer diferentes experimentações sobre a cultura corporal de movimento. Nesse contexto podemos observar as potencialidades da aproximação dos dois temas para a autenticidade da prática do esporte organizada e desenvolvida a partir de condições peculiares da instituição escola eseus atores. Assim, os alunos passam a visualizara Educação Física como disciplina, enão mais como uma atividade que apenas reproduz e ocupa o tempo.

\section{Referências}

BRACHT, V. Educação física e aprendizagem social. $2^{\text {a }}$ ed. Porto Alegre: Magister, 1997.

BRACHT, V; GONZÁLEZ, F. J. Educação Física Escolar. In: GONZÁLEZ, Fernando Jaime; FENSTERSEIFER, Paulo Evaldo.(Org.). Dicionário Crítico de educação física, ljuí: Unijuí, 2005.

CALDERÓN, A.; HASTIE, P.A.; PEREZ, D.M.O.; El modelo de educacion deportiva (Sport Education Model). Metodologia de enseñanza del nuevo milênio?. In: Revista Espñola de Educacion Física y Deportes, $n^{\circ}$ 395, p. 63-79, outubro-dezembro, 2011. Disponível em: < http://www.reefd.es/index.php/reefd/article/view/213/205> Acesso em: 03 fev.2017.

CARLAN, P; KUNZ, E; FENSTERSEIFER, P. E. O esporte como conteúdo da Educação Física escolar: estudo de caso de uma prática pedagógica "inovadora". In: Revista Movimento, Porto Alegre, v. 18, n. 04, p. 55-75, out/dez de 2012. Disponível em: < http:// www.seer.ufrgs.br/index.php/Movimento/article/view/29643> Acesso em: 24 mar.2017.

DARIDO, S. C. Educação Física na Escola: Conteúdos, duas Dimensões e Significados. 
Acervo digital da UNESP, 2012. Disponível em < http://www.acervodigital. unesp.br/bitstream/123456789/41549/1/01d19t03.pdf> Acesso em: 25 mai. 2016.

GINCIENE, G.; MATTHIESEN, S. Q. Modelo do sport education no ensino do atletismo na escola. Movimento, Porto Alegre, v. 23, n. 2, p. 729742, abr./jun. de 2017. Disponível em: <http://www.seer.ufrgs.br/index. php/Movimento/article/view/69788/42227>. Acesso em: 12 jul. 2017.

GIL, A. C. Como elaborar projetos de pesquisa. $4^{\text {a }}$ edição, SP, editora Atlas S.A. 2002.

GHIRALDELLI Jr, P. Educação Física Progressista. São Paulo: Loyola, 1988.

GONZÁLEZ, F. J.; FENSTERSEIFER, P. E. Entre o "não mais" e o "ainda não": pensando saídas do não-lugar da EF Escolar I. In: Cadernos de Formação RBCE, Florianópolis, v. 1, p. 9-24, set. 2009. Disponível em: <http://revista.cbce. org.br/index.php/cadernos/article/view/929/539> Acesso em: 08 set. 2016.

GONZÁLEZ, F. J.; FRAGA, A. B. Referencial Curricular de Educação Física. In: RIO GRANDE DO SUL/Secretaria de Estado da Educação/Departamento Pedagógico. Referenciais Curriculares do Estado do Rio Grande do Sul: Linguagens, Códigos e suas Tecnologias I Secretaria de Estado da Educação. Porto Alegre: SE/DP, 2009, v. 2. p. 113-181.

GRAÇA, A.; MESQUITA, I. A investigação sobre os modelos de ensino dos jogos desportivos. In: Revista Portuguesa de Ciências do Desporto, 7(3) 401421, 2007. Disponível em: < http://www.scielo.mec.pt/scielo.php?pid=S164505232007000300014\&script=sci_abstract $>$. Acesso em: 18 de fev. 2017.

KUNZ, E. Transformação Didático-Pedagógica do Esporte. $7^{\text {a }}$ ed. ljuí: Unijuí, 2010.

MACHADO, T. S; BRACHT, V. O impacto do movimento renovador da Educação Física nas identidades docentes: uma leitura a partir da "teoria do reconhecimento" de Axel Honneth. Revista Movimento. Porto Alegre, v. 22, n. 3, 849-860, jul./set. de 2016. Disponível em: < www.seer.ufrgs.br/Movimento/article/viewFile/60228/38854> Acesso em: 12 de mai. 2017.

OLIVEIRA, V. M. de. O que é Educação Física?. 10a ed. São Paulo: Brasiliense, 1993.

SIEDENTOP, D.: Sport education: Quality PE through positive sport experiences. Champaign, IL: Human Kinetics, 1994. 